\title{
Valorización turística de paisajes naturales. El caso de Mar del Plata, Argentina
}

\author{
Tourist valorisation of natural landscapes. \\ The case of Mar del Plata, Argentina
}

\author{
Noelia Aymara Padilla \\ Centro de Investigaciones Económicas y Sociales, Facultad de Ciencias \\ Económicas y Sociales, Universidad de Mar del Plata, Argentina \\ noeliaaymarapadilla@gmail.com
}

Recibido: 13/07/2018 • Aceptado: 15/05/2019

\section{RESUMEN}

La ciudad de Mar del Plata concentra el turismo de sol y playa del partido de General Pueyrredon (Argentina). Sin embargo, existen en el territorio otros paisajes naturales de tipo lagunar o serrano, cuya oferta turística aún es débil. El objetivo general de la investigación se centra realizar un diagnóstico de la valorización turística de distintos paisajes. Para ello, se identifican Unidades de Paisaje, su grado de protección ambiental y la presencia y posibilidad de uso turístico. La puesta en valor turístico de otros paisajes, más allá del litoral, puede contribuir a descomprimir la presión sobre las costas y diversificar la oferta turístico-recreativa, reduciendo los problemas de estacionalidad del destino. En virtud de un desarrollo turístico basado en la conservación de estos paisajes, cobran importancia los problemas de accesibilidad, infraestructura y equipamientos, así como el fortalecimiento de la protección ambiental.

\section{Noelia Aymara Padilla}


Palabras clave: turismo; paisaje natural; valorización turística

\begin{abstract}
The city of Mar del Plata concentrates the sun and beach tourism of the General Pueyrredon party (Argentina). However, there are other natural landscapes of lagoon or mountain type in the territory, whose tourist offer is still weak. The general objective of the research is making a diagnosis of the tourist value of different landscapes. For this, they identify Landscape Units, their degree of environmental protection and the presence and possibility of tourist use. The putting in value tourist of other landscapes, beyond the coast, can contribute to decompress the pressure on the coasts and diversify the tourist-recreational offer, reducing the problems of seasonality of the destination. In virtue of a tourism development based on the conservation of these landscapes, problems of accessibility, infrastructure and equipment become important; and the strengthening of environmental protection.
\end{abstract}

Keywords: tourism; natural landscape; tourist valorization.

\title{
INTRODUCCIÓN
}

La investigación se enmarca en la Geografía del Turismo, entendida por Pinassi y Ercolani (2014) como una "rama de la Geografía Humana, que centra su análisis en el turismo y sus múltiples vinculaciones con el territorio" (p. 13). Permite una visión holística de los paisajes naturales como recursos y atractivos turísticos y admite realizar un análisis que aborda el estudio físico, social y territorial, posible de ser aplicado a nivel local.

Uno de los conceptos esenciales de la Geografía del Turismo es el de Recurso Turístico, que según Domínguez de Nakayama (1993), lo constituyen "elementos con suficiente valor, atractivos, aptos y disponibles, sobre los cuales una comunidad puede basar su actividad turística" (p. 24). Así también, para la Organización Mundial del Turismo (OMT, 1978), el recurso turístico es el conjunto potencial (conocido o desconocido) de los elementos de la naturaleza y bienes materiales o inmateriales a disposición del hombre y que pueden utilizarse mediante un proceso de transformación, para satisfacer sus necesidades turísticas. 
Los recursos turísticos, según Domínguez de Nakayama (1993), deben cumplir tres condiciones básicas que definen la posibilidad de insertarse en la actividad turística: atractividad, aptitud y disponibilidad. La primera condición se relaciona con el valor estético y emocional de los recursos; es decir, que combina aspectos de la oferta, como por ejemplo, las cualidades intrínsecas y aspectos de la demanda como el conocimiento y la preferencia de los usuarios. La aptitud se refiere a la capacidad de uso de los bienes culturales y naturales y analiza su potencial para insertarse en la actividad turística. La disponibilidad se refiere a la accesibilidad física, temporal y administrativa. Finalmente, las facilidades son el complemento y sustento de los recursos. Dentro de este rubro se incluyen todas las instalaciones y equipamientos referidos al alojamiento, la gastronomía, el entretenimiento y la recreación y todos los servicios complementarios para el turista.

Tal como explica Lozato (1991), el medio físico natural constituye el factor condicionante en la localización de las actividades turísticas. Los recursos naturales permiten el desarrollo de distintas modalidades turísticas, tal como el Turismo de Naturaleza del que se desprenden el Ecoturismo, el Turismo de Sol y Playa, el Turismo de Aventura, entre otros. En este sentido, los paisajes naturales de un territorio pueden resultar en recursos turísticos capaces de estimular el desplazamiento, siendo contemplados o consumidos (Lozato, 1991).

El paisaje está integrado por elementos naturales y antrópicos, constituye la materialización de un instante de la sociedad y "conforma un conjunto de formas heterogéneas en donde distintas épocas y elementos quedaron subordinados a un movimiento global" (Santos, 1996, p. 64). Desde la perspectiva biofísica planteada por Mateo (2006), el paisaje es un Geosistema cuyos elementos naturales están relacionados de forma integrada. Por Unidad del Paisaje se entiende a aquellas porciones de la superficie terrestre provistas de límites naturales, donde los componentes abióticos y bióticos forman un conjunto de interacción e interdependencia, con una relativa homogeneidad a partir de procesos e interrelaciones de tipo geomorfológicos y ecológicos (López y Cervantes, 2000).

Los paisajes naturales se presentan en aquellos ambientes caracterizados por su naturalidad en un sentido relativo. Por oposición, se encuentra el 
paisaje antropizado (artificial), que es el que ha sido afectado por la presencia humana. Por lo cual, el paisaje natural puede describirse por:

- Promover la conservación de especies florísticas y faunísticas y sus ecosistemas, asegurando la continuidad para las generaciones futuras.

- Representar diferentes paisajes o formaciones geomorfológicas y su funcionamiento sistémico.

- Contribuir a las migraciones de especies, a las cadenas tróficas y a los ciclos biogeoquímicos.

- Permitir investigaciones científicas y de educación ambiental.

Con base en este marco teórico, la investigación se enfoca en la ciudad de Mar del Plata cabecera del partido de General Pueyrredon, provincia de Buenos Aires, Argentina (Figura 1). Constituye un importante puerto y principal destino balneario de la Argentina. La localidad presenta gran cantidad de paisajes naturales susceptibles de valoración turística, entre ellos: playas, acantilados, arroyos, lagunas y estribaciones del Sistema de Tandilia. Sin embargo, el turismo está enfocado en el litoral (playa) con una clara explotación de la playa, suscitándose diversas problemáticas ambientales propias del turismo masivo.

A partir de lo mencionado, el objetivo general de la investigación se centra en realizar un diagnóstico de la valorización turística de los distintos paisajes naturales de la ciudad de Mar del Plata. Para ello, se analiza el grado de protección ambiental y la presencia y posibilidades de uso turístico.

\section{METODOLOGÍA}

Se realiza un diagnóstico de la valorización turística de paisajes naturales de la ciudad de Mar del Plata. La metodología comprende un enfoque cualitativo que incluye un estudio exploratorio y descriptivo. El instrumento de recolección de datos incluyó la elaboración de fichas descripticas de cada paisaje, relevadas durante el verano del 2019 a partir de la observación directa y diversas referencias bibliografías. Ello permitió la descripción de 

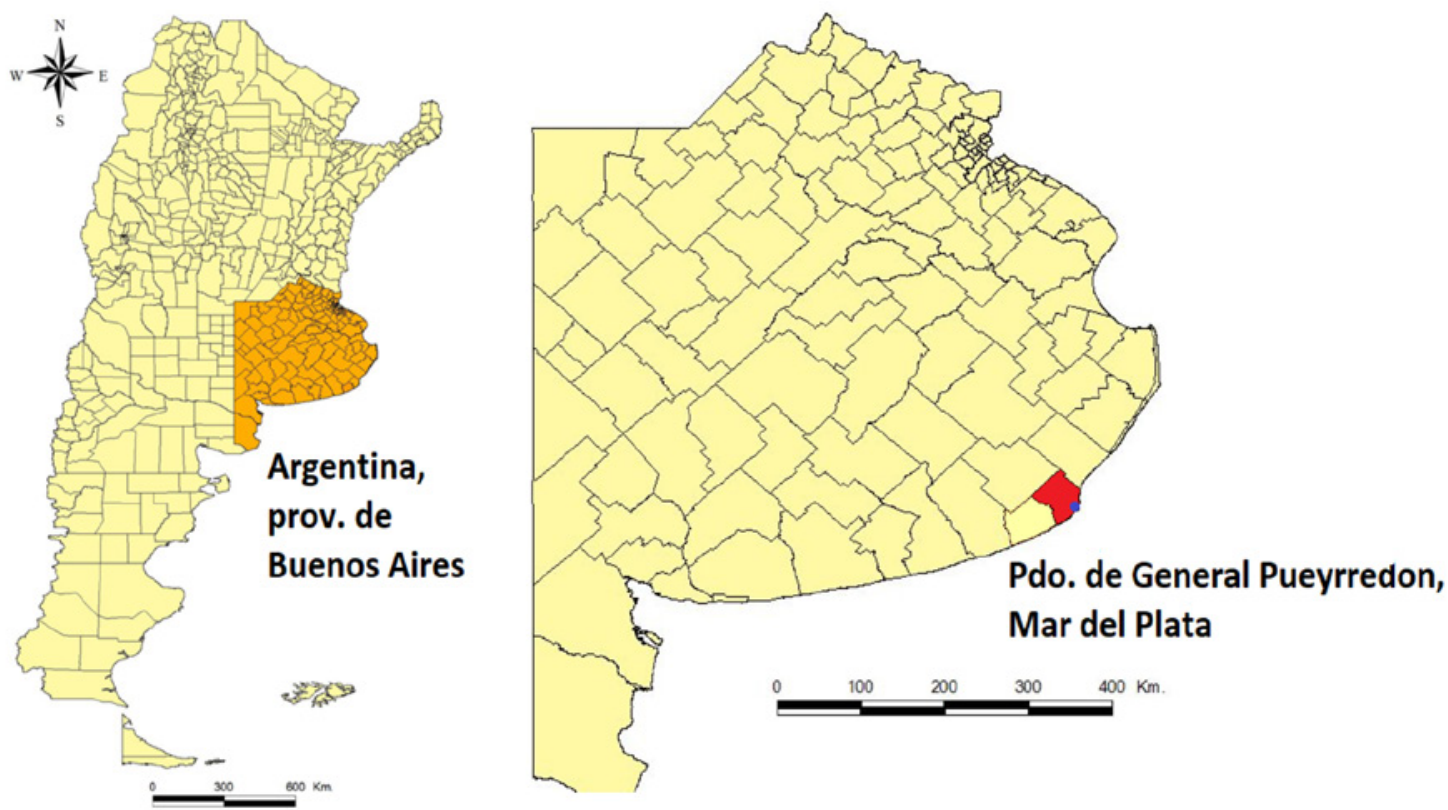

Figura 1. Mar del Plata, partido de General Pueyrredon, prov. de Buenos Aires, Argentina.

las Unidades de Paisaje y la elaboración de la tabla 1, donde se vuelcan los resultados de las variables de análisis.

La metodología de trabajo se dividió en dos etapas. Primeramente, se identificaron de Unidades de Paisajes, según la propuesta de López y Cervantes (2000), basado en la observación directa de atributos del sistema natural, usos del suelo, toma fotográfica e imágenes satelitales. Luego, se realizó el relevamiento de las siguientes variables con sus respectivos indicadores:

Variable 1: protección ambiental. Tiene en cuenta las especies faunísticas, florísticas o geoformas protegidas, el grado de protección (legislación y jurisdicción), la presencia de guardaparques y la acción de Organizaciones 
no Gubernamentales (ONG) conformadas por ciudadanos sin relación al ámbito privado ni gubernamental.

Variable 2: presencia y posibilidades de uso turístico. Tiene en cuenta el uso real o potencial turístico (alto/bajo); la cantidad de atractivos turísticos reconocidos por el organismo de turismo municipal (número de atractivos presentados en la oferta turística de Mar del Plata, naturales o culturales), la accesibilidad (presencia de vías de acceso y transporte público), las facilidades (presencia de infraestructura y equipamientos: miradores, estacionamientos, baños públicos) y modalidades y actividades turísticas que pueden implementarse sin que interfieran en la protección ambiental.

\section{La valorización turística del paisaje litoral}

El litoral de la localidad de Mar del Plata es un ambiente de playas sedimentarias, explotado turísticamente con gran diversidad de atractivos y equipamientos asociados a la presencia de balnearios (piletas, comercios, restaurantes, juegos para chicos, entre otros) reconocidos por el organismo de turismo y una buena accesibilidad. El turismo de sol y playa se ha caracterizado por su carácter masivo y la economía local es altamente dependiente a la estacionalidad de la actividad.

Sánchez (1985) explica que el turismo de litoral aparece cuando se produce la valoración social de ciertos elementos del medio físico. La base del turismo se fundamenta en la presencia de características físicas reunidas en un territorio concreto, el cual pasa así a convertirse en un espacio de ocio. De esta forma, el desarrollo del turismo de litoral en la ciudad de Mar del Plata, remite a convertirlo en un medio de producción específico, aprovechando ciertos factores físicos como la playa y el mar que llevan a su funcionalización turística.

El turismo se caracteriza con un marcado desequilibrio en términos espaciales (concentración en el litoral) y temporales (concentración en verano). La localidad de Mar del Plata presentó, en el último censo poblacional, 593 337 habitantes (Instituto Nacional de Estadística y Censos- INDEC, 2010). Sin embargo, aproximadamente 620000 turistas arribaron a la localidad en la primera quincena del año 2019, con un total de 4293392 de turistas durante todo el verano (del 1 de diciembre al 31 de marzo de 2019) (Ente Municipal de Turismo, EMTUR en La Capital 2019). 
La costa puede ser entendida desde la postura de Moreno (2007) como "uno de los territorios más problemáticos, en donde se ponen en contacto dos medios: el aire y el agua, interfieren el uno y en el otro y ambos están sujetos a la influencia de muchos factores, tanto físicos como químicos y climáticos" (p. 9). La valoración del litoral como espacio de ocio, sumado a la fragilidad del ambiente costero, llevó al surgimiento de diversivas problemáticas socio-ambientales que ponen en riesgo la sustentabilidad. Los impactos en el litoral marplatense fueron estudiados por diversidad de autores; entre ellos, García y Veneciano (2015), Di Meglio (2017) y Hernández (2016), que realizaron un análisis sobre la erosión costera, la contaminación por residuos sólidos, la disminución de heliofanía por edificios en altura, la disminución de espacio público por concesiones, entre otras problemáticas socio-ambientales.

Sin embargo, más allá del litoral, se identifican otros paisajes naturales de menor reconocimiento turístico de carácter lagunar (Reserva Natural Puerto Mar del Plata) y Serrano (estribaciones del Sistema de Tandilia), que constituyen parte de la base natural en la que se asienta la localidad. Estos paisajes, junto con la Lobería Escollera Sur, un espacio de asentamiento de Lobos Marinos de un pelo, presentan parte de la fauna y flora autóctona o de la geología originaria, por lo cual son identitarios del espacio y merecen ser conservados.

Fortalecer la identidad de un territorio puede contribuir al desarrollo local que, según Alburquerque (1997), implica un tipo de desarrollo endógeno, resultado del aprovechamiento de los recursos locales del territorio y alternativo al tipo de desarrollo concentrador basado en un enfoque vertical en la toma de decisiones. La dimensión ambiental del desarrollo local supone abordar la sustentabilidad de los procesos productivos y de los recursos.

\section{RESULTADOS}

\section{Descripción de paisajes naturales estudiados}

Se identifican tres Unidades del Paisaje caracterizados por presentar parte de la fauna y flora autóctona o de la geología originaria y distintiva: Reserva Natural Puerto Mar del Plata, Lobería Escollera Sur y Estribaciones del Sistema de Tandilia. A continuación, se presenta una breve descripción de estos paisajes. 


\section{a. Reserva Natural Puerto de Mar del Plata}

La Reserva del Puerto de Mar del Plata constituye un humedal de cuarenta hectáreas, con ecosistemas acuáticos, relicto del antiguo ecosistema de bañados costeros que ocupó más de quinientas hectáreas hasta finales de la década de los años setenta (Richeri, 2011). Su fauna se caracteriza por poseer más de ciento cincuenta especies de aves, pequeños mamíferos, reptiles, anfibios y peces. A su vez, es sitio de reposo y alimento de aves migratorias en sus rutas continentales, algunas provienen de Canadá. Su flora presenta gran variedad, la vegetación flotante está representada por la lenteja y el helechito de agua, cuya presencia forma tapices sobre las lagunas. Existen hierbas sumergidas, como lagambarrusa, y la concentración de algas en suspensión varía por estación, adquiriendo diversos matices de color verde (Fundación Reserva Natural Puerto Mar del Plata, 2013a). En el área de pastizal continental la especie predominante es la cortadera, con varias hectáreas de extensión (Figura 2).

La Reserva Natural Puerto Mar del Plata está ubicada entre un área industrial, el Puerto de Mar del Plata, una zona residencial y el Complejo Balneario de Punta Mogotes (Figuras 5). Actúa como espacio de amortiguamiento y moderación de las actividades industriales, residenciales y turísticas realizadas en dicha zona. Se pueden encontrar cinco ambientes identificados por la Fundación Reserva Natural Puerto Mar del Plata (2013b): paleoacantilado, laguna, pastizal, médanos y playas.

\section{b. Lobería Escollera Sur}

En el espacio portuario se encuentra también la Lobería Escollera Sur (Figura 3 y Figura 5), conformada por una colonia continental de lobos marinos machos de un pelo (Otaria flavescens). Constituye una pequeña área urbana protegida cuyo objetivo es conservar la colonia de pinnípedos más septentrional del país. Biológicamente, Chiozza y Figueira (1982) explican que el macho adulto es de color pardo oscuro, de cuello masivo, cabeza ancha, hocico corto y respingado. Todo su cuello está cubierto por una melena formada por una notoria capa de pelo castaño rojizo. Mide de 230 a $250 \mathrm{~cm}$ de largo y pesa alrededor de $300 \mathrm{~kg}$ (Figura 3). 


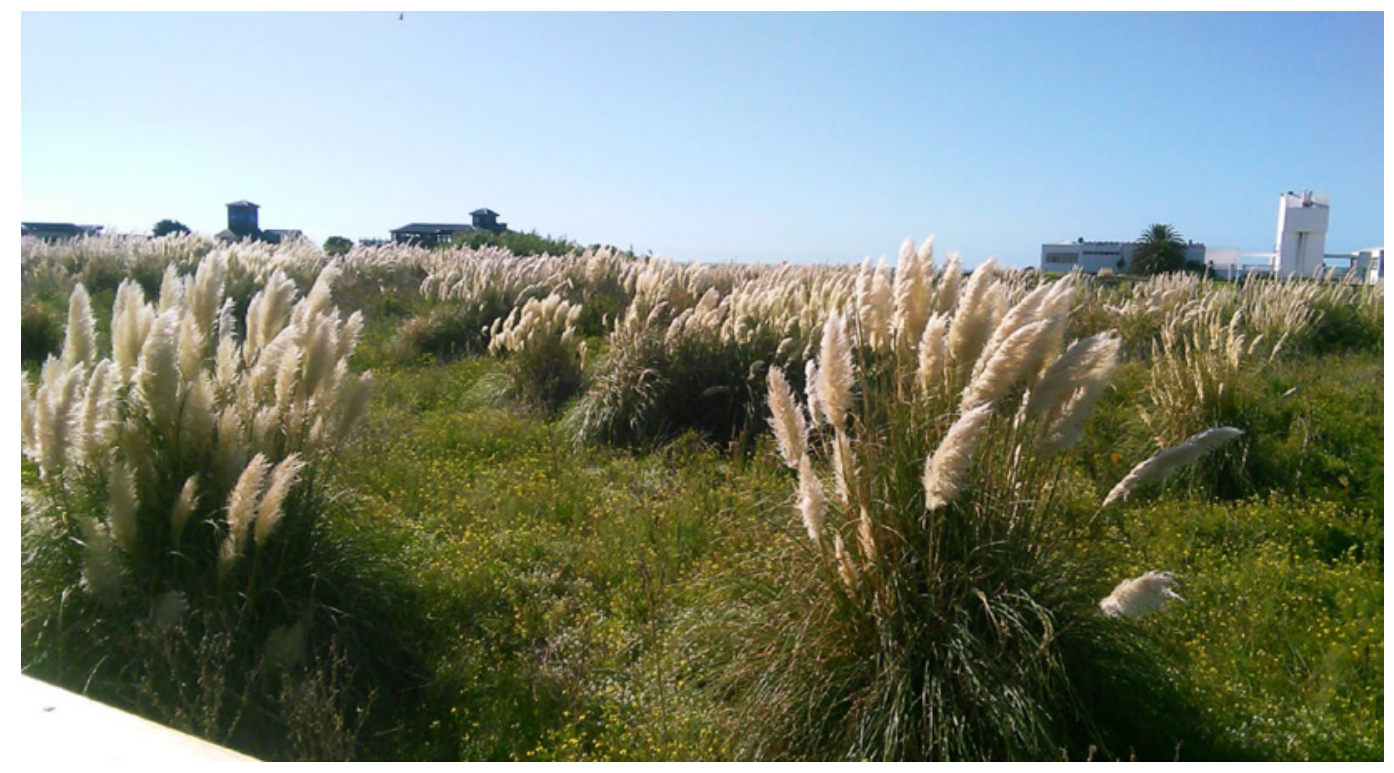

Figura 2. Reserva Natural Puerto Mar del Plata. Fuente: archivo personal (2019).

La colonia posee un carácter no reproductivo, al estar integrada casi exclusivamente por ejemplares machos. Esto se debe a que la especie posee un sistema de reproducción de tipo harén (Jefferson, Leatherwood, y Webber, 1993). Esta situación genera un excedente de machos, tanto los senescentes, los lesionados, los juveniles, entre otros, que tienden a agruparse para su protección en colonias no reproductivas.

La lobería se ubica en la Escollera Sur del puerto de Mar del Plata, caracterizada por poseer el mayor desembarque de productos pesqueros de la Argentina, siendo además cerealero de ultramar. Desde su inauguración en 1924, la presencia de los lobos ha constituido un conflicto con la actividad portuaria. Ello llevó a la localización actual de la lobería, el apostadero posee entre 230 y $330 \mathrm{~m}$ de largo por $40 \mathrm{~m}$ de ancho máximo, y presenta una orografía escalonada, distinguiéndose el nivel más elevado a la altura de los visitantes y el inferior con una amplia playa (Figura 3). 


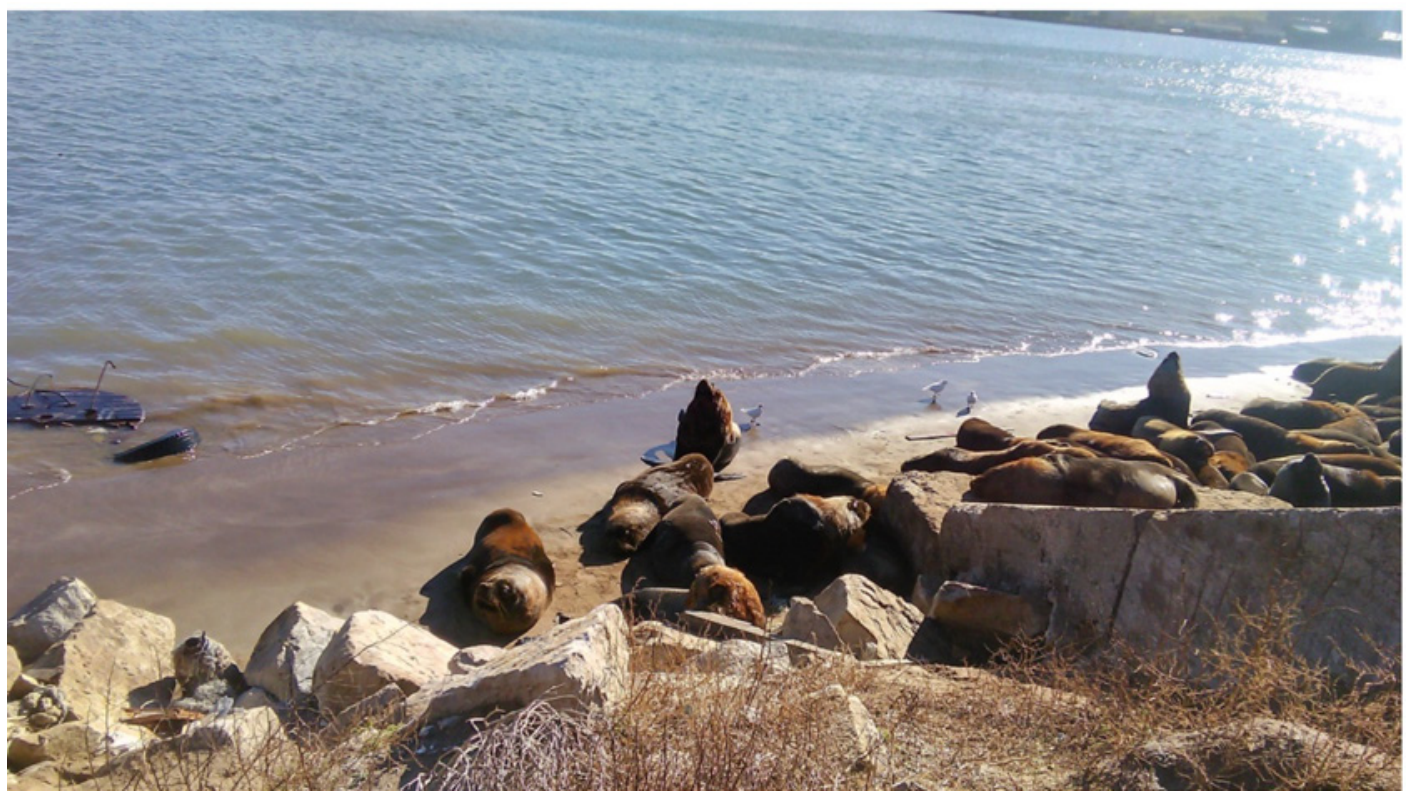

Figura 3. Lobería Escollera Sur. Fuente: archivo personal (2019).

\section{c. Estribaciones del Sistema de Tandilia}

En el litoral de Mar del Plata también es posible encontrar las últimas estribaciones del Sistema de Tandilia (Figura 4), un conjunto de sierras que cubre una longitud de unos $300 \mathrm{~km}$, un ancho de $60 \mathrm{~km}$ y una altura máxima de $525 \mathrm{~km}$ (De la Sota et al., 2004). Se extiende en la provincia de Buenos Aires, desde el partido de Olavarría (en Sierras Bayas a 15 $\mathrm{km}$ de la ciudad de Olavarría) hasta Cabo Corrientes, en Mar del Plata (Figura 5). Son las sierras de mayor antigüedad de Argentina, con unos 2200 millones de años.

Según explican Dalla et al. (2006), Tandilia se caracteriza por su larga historia geológica, diversidad de rocas ígneo-metamórficas, estructuras y por una cubierta precámbrica-eopaleozoica. Corre con un rumbo general noroeste-sudeste; es discontinuo, de relieve general bajo y su zona central se ensancha. Se reconocen tres grupos serranos principales: OlavarríaSierras Bayas-Azul, hacia el noroeste; Tandil-Barker, en el sector central; y Balcarce-Lobería-Mar del Plata, en el extremo sudoriental. En todos ellos, 
el basamento cristalino está expuesto, pero parcialmente cubierto en los extremos por las sedimentitas neoproterozoicas del Grupo Sierras Bayas (al norte) y las eopaleozoicas de la Formación Balcarce (al sur).

Las rocas cuarcitas que constituyen el sistema serrano en el tramo del partido de General Pueyrredon son aprovechadas por la actividad minera para la industria de la construcción. La roca extraída es utilizada para el revestimiento de viviendas y veredas y la construcción de escolleras en la localidad de Mar del Plata. En el kilómetro 8.5 de la Ruta $N^{\circ} 88$ se encuentran canteras a cielo abierto abandonas que generan paisajes de aprovechamiento turístico, aunque la actividad no se halla regulada.

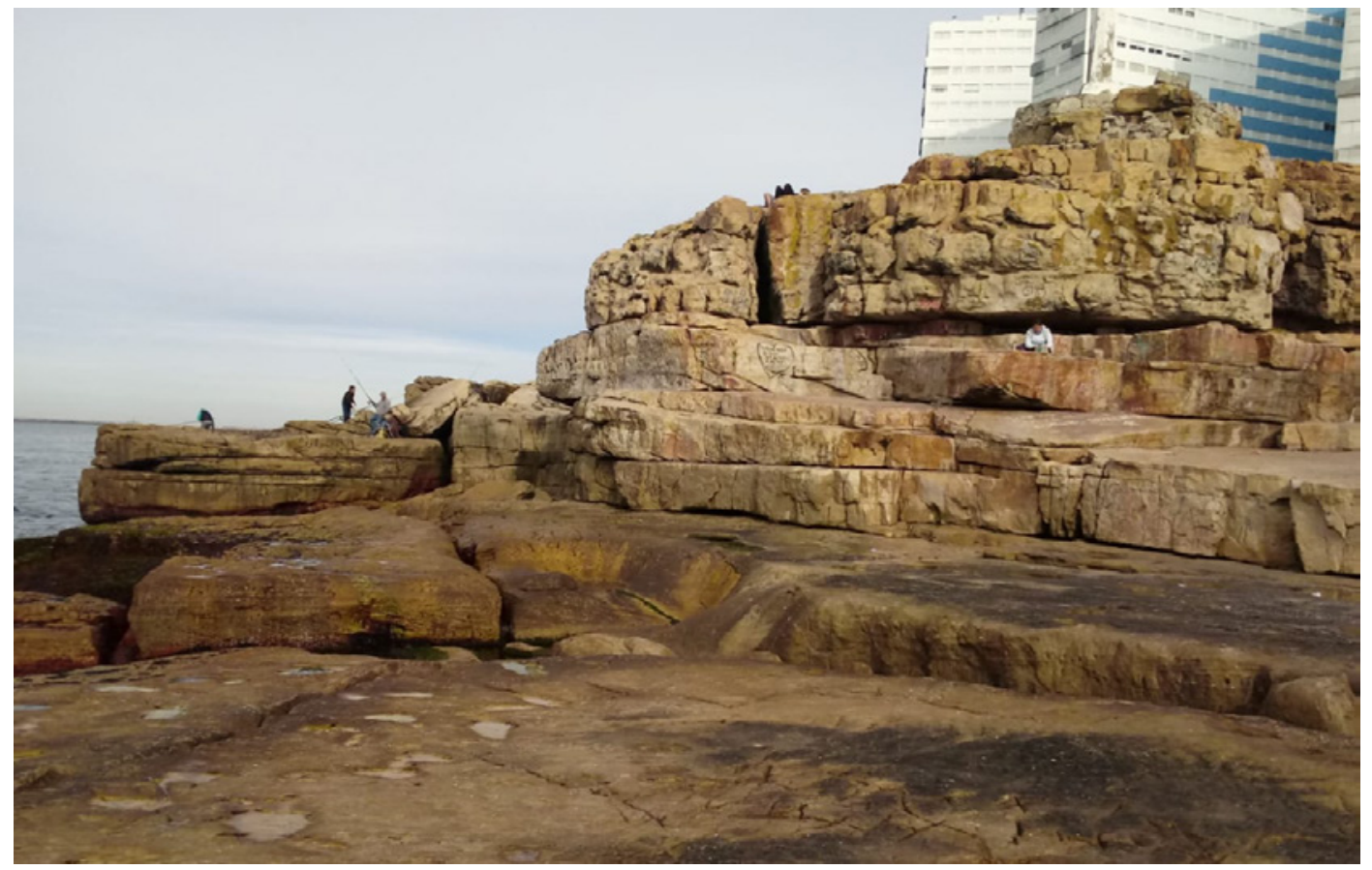

Figura 4. Estribaciones del sistema de Tandilia. Fuente: archivo personal (2019). 


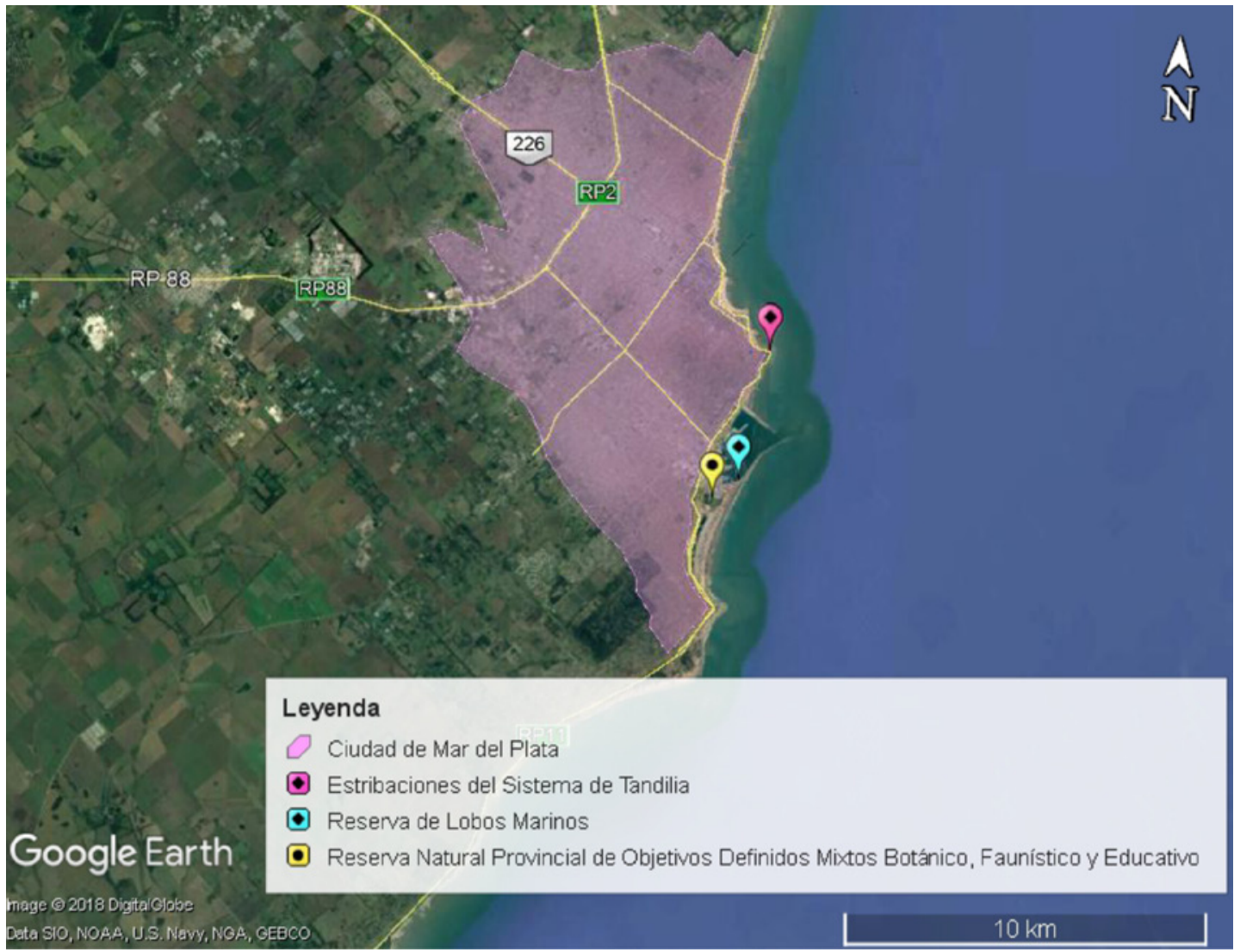

Figura 5. Localización de paisajes en estudio, Mar del Plata. Fuente: elaboración propia en base a Google Earth (2018).

\section{Protección ambiental, presencia y posibilidades de uso turístico}

La tabla 1 presenta los resultados del relevamiento de las variables de análisis: presencia y posibilidades de uso turístico y protección ambiental. 
Tabla 1

Presencia del turismo y características de conservación/protección en paisajes naturales

\begin{tabular}{|c|c|c|}
\hline Ambiente & Protección ambiental & $\begin{array}{l}\text { Presencia y posibilidades de uso } \\
\text { turístico }\end{array}$ \\
\hline $\begin{array}{l}\text { Reserva } \\
\text { Natural } \\
\text { Puerto Mar } \\
\text { del Plata }\end{array}$ & $\begin{array}{l}\text { Especies o geoformas protegidas } \\
\text { Fauna } \\
\text { Mamíferos: castores, liebre. } \\
\text { Peces: bagres, lisas. } \\
\text { Anfibios: ranita del zarzal y sapos (Bufo } \\
\text { arenarum y Bufo fernandezae). } \\
\text { Reptiles: culebras, lagartija. } \\
\text { Liolaemuswiegmanni (último relicto de la } \\
\text { especie dentro del partido). } \\
\text { Flora } \\
\text { Cortadera, espartillo, paja voladora, } \\
\text { senecio hunco totora, lenteja de agua y } \\
\text { el helechito de agua. } \\
\text { Geoformas } \\
\text { Médanos, playa y laguna. } \\
\text { Grado de protección } \\
\text { Legislación } \\
\text { Resolución del Consejo Deliberante } \\
\text { 247/89: Sitio de Interés Municipal, Turístico } \\
\text { y Recreativo. } \\
\text { Ordenanza Municipal 7927/90: Reserva } \\
\text { Natural. } \\
\text { Ley Provincial } 14.688 / 14: \text { Reserva Natural } \\
\text { Provincial de Objetivos Definidos Mixtos } \\
\text { Botánico, Faunístico y Educativo. } \\
\text { Jurisdicción } \\
\text { Provincial-municipal. } \\
\text { Presencia de guardaparques } \\
\text { Dos, no permanentes. } \\
\text { Acción de ONG } \\
\text { Fundación Reserva Natural Puerto: } \\
\text { actividades orientadas a la recreación, } \\
\text { educación, difusión y preservación del } \\
\text { ambiente natural de la reserva. Existe } \\
\text { también, una Estación de Recuperación de } \\
\text { Aves Marinas donde, una vez recuperados, } \\
\text { los ejemplares son trasladados por vía } \\
\text { aérea para su restitución en las colonias } \\
\text { de origen. } \\
\text { Greenpeace: apoyó el proyecto de ley } \\
\text { provincial. }\end{array}$ & $\begin{array}{l}\text { Uso turístico } \\
\text { Real: bajo. } \\
\text { Potencial: alto. } \\
\text { Atractivos } \\
\text { Naturales: laguna, médanos, pastizal } \\
\text { pampeano, playa (4). } \\
\text { Accesibilidad } \\
\text { Vías de acceso } \\
\text { No posee acceso propio, ingreso por } \\
\text { balneario Aguas Blancas. } \\
\text { Transporte público } \\
\text { Si (a menos de cinco cuadras) } \\
\text { Facilidades } \\
\text { Infraestructura: si (Avenida Dorrego, } \\
\text { Avenida Vertiz). } \\
\text { Equipamiento: sendero (en } \\
\text { realización), sin miradores (en } \\
\text { proyección), sin baños públicos, sin } \\
\text { estacionamiento propio. } \\
\text { Modalidades y/o actividades } \\
\text { turísticas posibles } \\
\text { Trismo de naturaleza contemplativo, } \\
\text { Turismo Educativo, Avistaje de Aves y } \\
\text { Senderismo. }\end{array}$ \\
\hline
\end{tabular}




\begin{tabular}{|c|c|c|}
\hline $\begin{array}{l}\text { Lobería } \\
\text { Escollera Sur }\end{array}$ & $\begin{array}{l}\text { Especies protegidas } \\
\text { Fauna: Lobos marinos de un pelo. } \\
\text { Grado de protección } \\
\text { Legislación } \\
\text { Ordenanza Municipal9440/94: Monumento } \\
\text { Natural Municipal (Artículo 1), de Interés } \\
\text { Municipal (Artículo 3). } \\
\text { Jurisdicción } \\
\text { Municipal. } \\
\text { Presencia de Guardaparques } \\
\text { No posee. } \\
\text { Acción de ONG } \\
\text { Fundación Fauna Argentina } \\
\text { Trabajó en preservar la lobería y buscar un } \\
\text { lugar seguro para que se establezcan. }\end{array}$ & $\begin{array}{l}\text { Uso turístico } \\
\text { Real: bajo. } \\
\text { Potencial: alto. } \\
\text { Atractivos } \\
\text { Naturales: Lobo Marino (1). } \\
\text { Accesibilidad } \\
\text { Vía de acceso: única vía por Escollera } \\
\text { Sur. } \\
\text { Transporte público (a diez cuadras). } \\
\text { Facilidades } \\
\text { Infraestructura: Escollera Sur, doble } \\
\text { circulación sin señalización. } \\
\text { Equipamiento: un mirador, sin área } \\
\text { de estacionamiento, sin baños } \\
\text { públicos. Se proyecta una edificación } \\
\text { que cuente con un centro de } \\
\text { interpretación y un sector para uso de } \\
\text { científicos y voluntarios que asistan a } \\
\text { los lobos. } \\
\text { Modalidades y/o actividades } \\
\text { turísticas posibles } \\
\text { Turismo de naturaleza. } \\
\text { Contemplativo. }\end{array}$ \\
\hline $\begin{array}{l}\text { Estribaciones } \\
\text { Sistema de } \\
\text { Tandilia }\end{array}$ & $\begin{array}{l}\text { Especies protegidas } \\
\text { No posee } \\
\text { Grado de protección } \\
\text { No posee } \\
\text { Presencia de Guardaparques } \\
\text { No posee } \\
\text { Acción de ONG } \\
\text { No posee }\end{array}$ & $\begin{array}{l}\text { Uso Turístico } \\
\text { Real: alto. } \\
\text { Potencial: alto. } \\
\text { Accesibilidad } \\
\text { Vías de acceso: varias. } \\
\text { Transporte público: varios. } \\
\text { Atractivos } \\
\text { Naturales } \\
\text { Rocas sedimentarias, } \\
\text { Playa Cabo Corrientes; Playa Chica } \\
\text { (3). } \\
\text { Culturales } \\
\text { Monumento a Guillermo Brown (1). } \\
\text { Facilidades } \\
\text { Equipamiento } \\
\text { Restaurantes, balneario, residencias } \\
\text { (edificios). } \\
\text { Infraestructura } \\
\text { Paseo Jesús de Galíndez, Boulevard } \\
\text { P. Peralta Ramos. } \\
\text { Modalidades y/o actividades } \\
\text { posibles } \\
\text { Turismo basado en la naturaleza } \\
\text { contemplativo, Turismo de Sol y Playa }\end{array}$ \\
\hline
\end{tabular}

Fuente: elaboración propia (2018). 
La tabla 1 permite dar cuenta que el uso y valorización turística de la Reserva Natural Puerto Mar del Plata, la Lobería Escollera Sur o las Estibaciones de Tandilia, ambientes identitarios del espacio, es desigual y escasa. Desde el punto de vista de la infraestructura y equipamiento turístico, existe una debilidad en el área de la Reserva del Puerto o de la Lobería Escollera Sur.

En el caso del primero de ellos, si bien se identifican vías de acceso como avenidas, no presentan acceso propio, ya que su ingreso es obligatoriamente por el balneario privado Aguas Blancas. Así también, no presenta equipamientos que contribuye al desarrollo del turismo en la naturaleza, tales como miradores o centros de interpretación, baños públicos, estacionamiento propio.

En el caso de la Lobería Escollera Sur, si bien presenta un mirador, no posee espacios de estacionamiento y la accesibilidad muestra una clara debilidad, ya que requiere el ingreso en vehículo particular o el acceso a pie de $1 \mathrm{~km}$ por la escollera, donde no existe una división entre el espacio para tránsito de vehículos del peatonal, ni señalización para el doble tránsito vehicular. En el caso de las estribaciones del Sistema de Tandilia se observa una mayor cantidad de equipamientos e infraestructura asociados a la valorización de la vista al mar. Sin embargo, no presentan carteles indicadores ni miradores que permitan informar sobre la importancia ecológica de este paisaje geológico.

En el año 2019 comenzó la implementación de un proyecto impulsado por el Consorcio Regional del Puerto de Mar del Plata, de puesta en valor turístico de la Reserva Natural Puerto Mar del Plata. Implicó la construcción de una pasarela en madera y sobre pilotes, con áreas de descanso y observación. En la actualidad, ha finalizado el primer tramo de la pasarela (500 m), que permiten observar el pastizal, la laguna y la playa. Se prevé que en su segundo trayecto integre la reserva con la Lobería Escollera Sur, constituyendo el Paseo Turístico Integrador del Puerto. El proyecto cuenta con el respaldo de Greenpeace, la Fundación Puerto Mar del Plata, AVATAR y unidades académicas como la Universidad Nacional de Mar del Plata y la Universidad FASTA.

Desde el punto de vista de la protección de estos espacios, la Reserva del Puerto presenta la conservación de especies faunísticas y florísticas 
en un territorio delimitado y la designación de una categoría de protección (Reserva Natural Provincial de Objetivos Definidos Mixtos Botánico, Faunístico y Educativo). Ello posee una clara relación con el rol de las ONG Fundación Reserva Natural Puerto y Greenpeace. En este sentido, en el año 2010 la Justicia Federal ordenó suspender la construcción de un estadio del club de fútbol Aldosivi en el área de la Reserva Natural del Puerto (Greenpeace, 2011). El proyecto implicaba, también, la construcción de una pileta y un gimnasio. Distintas ONG (Fundación Reserva Natural Puerto, Greenpeace), asociaciones vecinales (Asamblea de Vecinos Autoconvocados Trabajando en Acciones por la Reserva, AVATAR) y cámaras empresarias presentaron un recurso de amparo argumentando incompatibilidad y un posible impacto ambiental negativo. A pesar que la Justicia Federal intimó al Club Aldosivi y estableció el cese de los trabajos de construcción, se destruyó cerca del $25 \%$ de la reserva (Greenpeace, 2011), sin una Evaluación de Impacto Ambiental previa como establece la Ley provincial $\mathrm{N}^{\circ} 11.723$. Este suceso llevó a la sanción de la Ley Provincial 14688/14 (tabla 1).

En la actualidad la reserva presenta usos incompatibles a la protección ambiental, tales como el tránsito ilegal en cuatriciclos en el sector de playas. Esta actividad genera aplanamiento de médanos y afecta la fauna medanosa (Lagartija Liolaemuswiegmanni). Es por ello que la presencia de guardaparques permanentes se vuelve indispensable.

Para el caso de la Lobería Escollera Sur, a comienzos de la década de 1980, ante la aparición de lobos lastimados por conflictos con la actividad portuaria, se crea la Fundación Fauna Argentina. En el año 2002, el Consorcio Portuario Regional otorgó a la fundación un sector del puerto lindero a la Escollera Sur para la reubicación de los mamíferos. Sin embargo, en la actualidad, los lobos aún sufren la interacción negativa con la actividad pesquera porque consumen parte de la captura de la pesca mediante redes de agalla. Así también, se destaca la mortalidad de lobos por captura incidental en operaciones pesqueras de diversos artes de arrastre de fondo y pelágicos. Indirectamente, también sufren la explotación pesquera de las presas que ellos habitualmente capturan (Dans, Koen, Crespo, Pedraza, y García, 2003).

La protección y conservación de las especies faunísticas de la lobería es muy débil, situación que se manifiesta con la presencia de animales 
lastimados, a pesar de ser el lobo marino un hito representativo de las postales de la ciudad de Mar del Plata. Los conflictos con la actividad pesquera, junto con los ataques de perros callejeros, ponen en riesgo su seguridad. Desde hace décadas, la Fundación Fauna Argentina se hace cargo de la protección de las especies, curando a los animales lastimados y manteniendo el lugar en condiciones, sin respuesta de los sucesivos gobiernos comunales ni de organismos oficiales.

\section{DISCUSIÓN}

La localidad de Mar del Plata tradicionalmente prioriza el turismo de sol y playa. La valorización de otros paisajes naturales, como la Reserva Natural Puerto Mar del Plata, la Lobería Escollera Sur y las Estribaciones del Sistema de Tandilia puede contribuir a descomprimir la presión sobre los recursos de la costa y diversificar la oferta turístico-recreativa, reduciendo los problemas de estacionalidad del destino. Ello requiere la implementación de diversos programas y su financiamiento por parte del Ente Municipal de Turismo o la Secretaría de la Provincia de Buenos Aires, de acuerdo con la jurisdicción de los casos presentados, que permitan impulsar el Turismo de Naturaleza.

En este sentido, para el caso de la Reserva Natural Puerto de Mar del Plata, se requiere dotar de equipamientos que permitan proporcionar un mejor acceso, el establecimiento de miradores y baños públicos. Así también, fortalecer la presencia de guardaparques para evitar usos incompatibles que afectan la protección del lugar. Para el caso de la Lobería Escollera Sur, resulta necesario el establecimiento de infraestructura que permita mejorar la circulación y el acceso al lugar.

Desde el punto de vista de la protección ambiental, se observa una debilidad que requiere reflexionar sobre la necesidad de un marco normativo y categoría de protección mayor. Finalmente, en el caso de las Estribaciones del Sistema de Tandilia, si bien el paisaje es valorizado turísticamente, ello se debe al litoral como espacio turístico-recreativo, el paisaje rocoso no presenta carteles indicadores ni miradores que permitan informar sobre la importancia geológica del lugar.

Cobra interés integrar los paisajes naturales a la oferta turística del partido; en este sentido, la implementación de circuitos turísticos integrados que vinculen los paisajes naturales, tal como es el caso del Paseo Turístico 
Integrador del Puerto, constituye una oportunidad de puesta en valor turístico. Desde el punto de vista ambiental, la valorización turística de estos espacios debe incluir el desarrollo de actividades recreativas de apreciación y conocimiento de la naturaleza con base en la conservación de los ecosistemas. La protección mediante la declaración del área natural como protegida reconoce la importancia natural del territorio, pero cobra importancia conjugar la protección y conservación de los espacios con el desarrollo de las actividades turísticas. La sobrecarga de usos en el territorio pone en peligro la distinción natural, es por ello que la valorización turística debe considerar:

- adoptar medidas de conservación de las especies faunísticas y florísticas.

- implementar visitas educativas que permitan entender y difundir el contenido geológico y geográfico, así como el desarrollo responsable del turismo basado en un uso controlado.

- $\quad$ promover la investigación geológica, situación que puede ser acompañada con actividades educativas y de concientización de la geodiversidad del lugar.

- $\quad$ ofrecer medios de interpretación a través de señalética.

\section{REFERENCIAS}

Alburquerque, F. (1997). Metodología para el Desarrollo Económico Local. Santiago, Chile: ILPES. Chiozza y Figueira (1982). El lobo marino de un pelo. Revista Fauna Argentina. № 33 CEAL. Buenos Aires, Argentina.

Dalla, L., Spalletti, L., Poiré, D., De Barrio, R., Echeveste, H., y Benialgo, A. (2006). Tandilia. Serie Correlación Geológica, 21(1), 17-46.

Dans, S., Koen, M., Crespo, E., Pedraza, S., y García, N. (2003). Interactions between Marine Mammals and High Seas Fisheries in Patagonia Under an Integrated Approach. In N. Gales, M. Hindell y R. Kirkwood (Eds.) Marine Mammals: Fisheries; Tourism and Management Issues. Clayton, Australia: CSIRO Publishing. 
De la Sota E., Giuduce, G., Ponce M., Ramos Giacosa J., y Artur, M. (2004). Relaciones fitogeográficas de la flora pteridofítica serrana bonaerense. Boletín Sociedad Argentina de Botánica, 39(3-4): 181-194.

Di Meglio, R. (2017). Reflexiones en torno al concepto de espacio público en la playa a partir del caso del Complejo Playa Grande, Mar del Plata, Argentina. En /l Congreso Latinoamericano de Teoría Social y Teoría Política: Horizontes y dilemas del pensamiento contemporáneo en el sur global. Congreso llevado a cabo en Buenos Aires, Argentina.

Domínguez De Nakayama, L. (1993). Relevamiento turístico. Propuesta metodológica para el estudio de una unidad territorial. Santa Fe, Argentina: Instituto Superior de Turismo Sol.

Fundación Reserva Natural Puerto Mar del Plata. (2013a). Flora. Buenos Aires, Argentina. Autor.

Fundación Reserva Natural Puerto Mar del Plata. (2013b). Ambientes. Buenos Aires, Argentina: Autor.

Jefferson, T., Leatherwood, S., y Webben, M. (1993). Species identification guide. Marine Mammals of the World. Roma, Italia: FAO.

García, M. C. y Veneciano, M. F. (2015). Análisis FPEIR sobre rompeolas y playas regeneradas en el sur de Gral. Pueyrredón, Argentina. Contribuciones Científicas GÆA, (27), 93-108.

Greenpeace. (2011). Salva la reserve del puerto Mar del Plata. Campaña Reserva Natural Puerto. Grupo Local de Valuntarios Mar del Plata. Greenpeace. Recuperado de https://www.rionegro.com.ar/wp-content/uploads/documents/1/0/3364079.pdf

Hernández, F. (2016). Análisis del paisaje turístico de la costa marítima de la provincia de Buenos aires. Entrevistas Revista de Debate, 7(8).

Instituto Nacional de Estadística y Censos. [INDEC]. (2010). Censo 2010. Recuperado de https://www.indec.gob.ar/ 
La Capital Mar del Plata (2019). Al final, el EMTUR dio a conocer las cifras de la temporada: llegaron más de 3 millones de turistas. Recuperado de https://www.lacapitalmdp.com/al-final-el-emtur-dio-a-conocer-lascifras-de-la-temporada-llegaron-mas-de-3-millones-de-turistas/

López, R. y Cervantes, J. (2000). Unidades del paisaje para el desarrollo sustentable y manejo de los recursos naturales. Revista de Información y Análisis, 20, 43-49.

Lozato, J. (1991). Geografía del Turismo. Del espacio contemplado al espacio consumido. Barcelona, España: Editorial Masson.

Mateo, J. (2006). La concepción sobre los paisajes vista desde la Geografía. Boletín de Geografía, 24 (1), 1-25

Moreno, I. (2007). Manejo Integral Costero. Por una costa más ecológica, productiva y sostenible. Palma de Mallorca, España: Universitat de les Illes Balears

Organización Mundial de Turismo. [OMT]. (1978). Evaluación de los recursos turísticos. Madrid, España: Autor.

Pinassi, A. y Ercolani, P. (2014). Geografía del Turismo: análisis de las publicaciones científicas en revistas turísticas. El caso de Argentina. Cuadernos de Geografía: Revista Colombiana de Geografía, 24(1), 213-230. doi: 10.15446/rcdg.v24n1.47778

Richeri, P. (2011). Las lagunas urbano-costeras de Punta Mogotes, síntesis diacrónica y sincrónica de sus transiciones. Párrafos Geográficos, 10(2), 38-52.

Sánchez, J. E. (1985). Por una Geografía del Turismo de Litoral. Una aproximación metodológica. Estudios Territoriales, 17, 103- 122.

Santos, M. (1996). La naturaleza del espacio. Técnica y tiempo. Razón y emoción. Barcelona, España: Ariel. 